University of Nebraska - Lincoln

DigitalCommons@University of Nebraska - Lincoln

Faculty Publications: Department of Entomology

3-14-2019

\title{
Vapor delivery of plant essential oils alters pyrethroid efficacy and detoxification enzyme activity in mosquitoes
}

Scott T. O'Neal

Ellis J. Johnson

Leslie Catherine Rault

Troy D. Anderson

Follow this and additional works at: https://digitalcommons.unl.edu/entomologyfacpub

Part of the Chemicals and Drugs Commons, Disorders of Environmental Origin Commons, and the Entomology Commons

This Article is brought to you for free and open access by the Entomology, Department of at DigitalCommons@University of Nebraska - Lincoln. It has been accepted for inclusion in Faculty Publications: Department of Entomology by an authorized administrator of DigitalCommons@University of Nebraska - Lincoln. 


\title{
Vapor delivery of plant essential oils alters pyrethroid efficacy and detoxification enzyme activity in mosquitoes
}

\author{
Scott T. O'Neal, Ellis J. Johnson, \\ Leslie C. Rault, Troy D. Anderson \\ Department of Entomology, University of Nebraska, Lincoln, NE, USA \\ Corresponding author —S.T. O'Neal, email soneal3@unl.edu
}

\begin{abstract}
The use of synthetic insecticides to limit the spread of mosquito-borne disease faces a number of significant challenges, including insecticide resistance, concerns related to the environmental impact of widespread insecticide use, as well as slowed development of new insecticide chemistries. One important alternative to broadcast insecticides is the use of personal protection strategies to limit contact with vector species, including the use of spatial repellents that can employ synthetic pyrethroids or botanical products to effect control. A currently underexplored area of research involves the investigation of botanical products for their potential to serve as insecticide synergists when delivered as a vapor. This study describes the development of an assay that facilitates the screening of essential oils delivered as a vapor for enhancement of deltamethrin efficacy in both pyrethroid-susceptible and -resistant strains of the vector mosquito species Aedes aegypti. Deltamethrin efficacy was significantly increased following exposure to cinnamon (Cinnamomum cassia),
\end{abstract}

Published in Pesticide Biochemistry and Physiology 157 (2019), pp 88-98.

doi 10.1016/j.pestbp.2019.03.007

Copyright (c) 2019 Elsevier Inc. Used by permission.

Submitted 24 January 2019; revised 5 March 2019; accepted 13 March 2019; published

14 March 2019 
tagetes (Tagetes bipinnata), and sage (Salvia officinalis) oils, while efficacy was significantly decreased following exposure to amyris (Amyris balsamifera) oil. These effects appeared to be mediated by changes in cytochrome P450 activity. This work demonstrates that some plant-derived essential oils delivered as a vapor are capable of increasing the efficacy of deltamethrin similar to classical synergists such as piperonyl butoxide, supporting the use of a real world delivery method instead of traditional contact exposure studies.

Keywords: Mosquito, Aedes aegypti, Plant essential oils, Vapor, Synergism

\section{Introduction}

Aedes aegypti is a globally distributed vector mosquito species that poses a serious threat to human health due to its role in the transmission of viral pathogens such as chikungunya, dengue, yellow fever, and Zika viruses (Gubler, 2010; Fauci and Morens, 2016). Despite the variety of different biological, chemical, cultural, and mechanical control strategies that have been developed to combat this problem, the chemical control of vector mosquito populations using insecticides remains the primary approach for limiting the spread of mosquitoborne disease (Rozendaal and World Health Organization., 1997). This reliance on chemical control strategies has imposed significant selection pressure on vector mosquito populations, resulting in the widespread development of resistance to virtually all classes of insecticides (Hemingway and Ranson, 2000; Nauen, 2007). Further complicating this issue are the high cost and slow pace of the development of new insecticide chemistries, a lack of novel target sites, as well as growing concerns about the non-target and environmental impacts of widespread insecticide use. Consequently, there is a growing emphasis on personal protection strategies managed at the individual level to limit human contact with vector mosquitoes in order to reduce the risk of pathogen transmission (CDC, 2016).

The disruption of host-seeking behavior through the use of topical repellents such as the widely-used and highly effective compound $N, N$ diethyl-meta-toluamide (DEET) is an important component of a successful vector management strategy. An alternative approach to the use of topical repellents is the use of spatial repellents, which consist of highly volatile compounds that diffuse throughout the air in a treated space in the form of a vapor that can repel or even kill exposed 
mosquitoes (Achee et al., 2012). Spatial repellents that are currently available on the consumer market either employ synthetic pyrethroids or a wide array of plant-based products that are delivered using passive delivery devices such as candles, coils, emanators, heated elements, or vaporizers to volatilize and distribute the product (Norris and Coats, 2017; Bibbs et al., 2018). Various studies have investigated the toxicity of pyrethroid-based spatial repellents in several mosquito species in order to assess their utility as adulticides (Abdel-Mohdy et al., 2008; Rapley et al., 2009; Xue et al., 2012; Ritchie and Devine, 2013; Bibbs and Xue, 2016; Bibbs et al., 2018). An area that has yet to be explored, however, is the possibility of enhancing pyrethroid effectiveness in a vapor delivery model using volatile insecticide synergists.

A common tool, both in research and in commercial mosquito control products, is the use of chemical synergists such as piperonyl butoxide (PBO), which is capable of increasing insecticide efficacy by inhibiting metabolism of the insecticide by microsomal cytochrome P450-dependent monooxygenation (Matthews and Casida, 1970). PBO and other synergists can thus aid in determining mechanisms of insect resistance, increase the spectrum of activity of an insecticide, decrease insecticide costs by reducing the amount of active ingredient required, and potentially overcome metabolic resistance in certain resistant insect strains (Metcalf, 1967). Efforts to identify alternatives to PBO, which is currently the commercial standard, have led to a growing body of work that examines plant-based products such as essential oils for synergistic properties against insects (Belzile et al., 2000; Pavela, 2008; Joffe et al., 2012; Tong and Bloomquist, 2013; Faraone et al., 2015; Tak and Isman, 2015; Tak et al., 2015; Gross et al., 2017; Norris et al., 2018). This work parallels, and often complements, the investigation of essential oils and other botanical products as pesticides for the control of mosquitoes (Dias and Moraes, 2014; Norris et al., 2015), as well as novel mosquito repellents (Rehman et al., 2014; Gross and Coats, 2015).

While there have been a select few studies that have explored synergistic effects of essential oils with one another in a fumigation assay (Pavela, 2008; Tak and Isman, 2015; Tak et al., 2015), there have been no reported studies that address the potential of essential oils delivered as a vapor to enhance the efficacy of insecticides. Therefore, the objective of the work presented here was to develop an assay that 
would facilitate the screening of essential oils delivered as a vapor for enhancement of pyrethroid efficacy in both pyrethroid-susceptible and -resistant strains of the vector mosquito species Aedes aegypti. Essential oils demonstrating synergism were tested more extensively in both vapor and topical delivery assays, then tested in assays of detoxification enzyme activity in order to better understand the likely mode of action by which synergism was produced.

\section{Materials and methods}

\subsection{Mosquito strains}

Two strains of Aedes aegypti mosquitoes were used in this study: a susceptible laboratory strain, Rockefeller (Rock), established in 1937 (obtained through BEI Resources, NIAID, NIH: Aedes aegypti ROCKEFELLER, MRA-734), and a pyrethroid resistant strain, Puerto Rico (PR), from San Juan, Puerto Rico, and maintained in the laboratory under selection pressure since 2012 (obtained through BEI Resources, NIAID, NIH: Aedes aegypti PUERTO RICO, MRA-NR-48830). Eggs from each strain were reared to adulthood separately. Adult mosquitoes were aspirated after emergence and age was measured in number of days post emergence. Mosquitoes were kept in environmental chambers at $27{ }^{\circ} \mathrm{C}$ and 70 to $80 \%$ relative humidity with a photoperiod of 12:12 (light:dark). Adults were kept in screened cages and provided with $10 \%$ sucrose solution. In order to produce eggs, female mosquitoes were provided a blood meal of defibrinated sheep blood (Remel Incorporated, San Diego, CA) using an artificial glass mosquito feeder (Chemglass Life Sciences LLC, Vineland, NJ) and allowed to oviposit on seed paper (Anchor Paper Company, Saint Paul, MN). Eggs were hatched and larvae were reared in plastic containers partially filled with distilled water at approximately $25^{\circ} \mathrm{C}$. Larvae were fed ground fish food flakes (TetraMin, Melle, Germany). Pupae were transferred to a $100 \mathrm{~mL}$ beaker containing distilled water and were placed in an adult cage for emergence. For all assays, test subjects consisted of non-blood fed, 3 to 5 days old adult female mosquitoes that were anesthetized on ice prior to handling or treatment. 


\subsection{Chemicals}

Acetone, bicinchoninic acid solution, bovine serum albumin, 7- ethoxycoumarin (7-EC), $\beta$-nicotinamide adenine dinucleotide phosphate (reduced $\beta-N A D P H)$, oxidized glutathione, glutathione reductase, acetonitrile, TRIZMA-base, umbelliferone (7-hydroxycoumarin), $\alpha$-naphthyl acetate $(\alpha-N A)$, Triton $X-100$, fast blue B salt (O-dianisidine, tetrazotized), sodium dodecylsulfate (SDS), $\alpha$-naphthol, glutathione, and 1-chloro-2, 4-dinitro-benzene (CDNB) were purchased from Sigma (St. Louis, MO, USA). Technical grade piperonyl butoxide (PBO) and deltamethrin were obtained from Chem Service, Inc. (West Chester, $\mathrm{PA}, \mathrm{USA}$ ) and diluted in acetone to the appropriate concentration. A $10 \mathrm{mM}$ dose of PBO and a median lethal dose (LD50) of deltamethrin, based on mosquito strain and exposure time, were used for all relevant experiments. The required concentrations of deltamethrin were determined in separate dose-response assays using either $1 \mathrm{~h}$ or $24 \mathrm{~h}$ mortality endpoints. Rock mosquitoes received $0.3 \mu \mathrm{M}$ deltamethrin for $1 \mathrm{~h}$ and $0.07 \mu \mathrm{M}$ for $24 \mathrm{~h}$ mortality bioassays, whereas PR mosquitoes received $10 \mu \mathrm{M}$ for $1 \mathrm{~h}$ and $5 \mu \mathrm{M}$ for $24 \mathrm{~h}$ mortality bioassays. The topical insect repellent DEET ( $N, N$-Diethyl-meta-toluamide), obtained from Chem Service, Inc. (West Chester, PA, USA), and 31 essential oils, listed in Table 1, were screened for this study. In topical bioassays, essential oils were diluted in acetone to a $0.1 \%$ solution based on preliminary trials in order to minimize treatment mortality. All topical treatments were applied using a Hamilton PB600 repeating dispenser equipped with a $10 \mu \mathrm{L}$ gas-tight Hamilton syringe (Reno, NV, USA). Essential oils were not diluted for assays using vapor delivery, but DEET was diluted to $25 \%$ solution in acetone.

\subsection{Vapor bioassays}

Vapor bioassays were designed to expose adult mosquitoes to essential oil vapors in an open air testing environment in order to assess their ability to enhance the efficacy of topically-applied deltamethrin. Topical application of insecticide was used to reduce variability and improve the consistency of results. The testing apparatus consisted of a $32 \mathrm{oz}$. (ca. $946 \mathrm{~mL}$ ) white double poly-coated paper soup cup (top diameter: $4.5 \mathrm{in} / 114.3 \mathrm{~mm}$, bottom diameter: $3.5 \mathrm{in} / 88.9 \mathrm{~mm}$, 
Table 1. Listing of essential oils products screened in this study.

\begin{tabular}{|c|c|c|}
\hline Common name & Scientific name & Manufacturer \\
\hline Amyris & Amyris balsamifera & BioSource Naturals, Canton, MI, USA \\
\hline Basil & Ocimum basilicum & Puritan's Pride, Oakdale, NY, USA \\
\hline Black pepper & Piper nigrum & Edens Garden, San Clemente, CA, USA \\
\hline Cajuput & Melaleuca cajuputi & Edens Garden, San Clemente, CA, USA \\
\hline Camphor & Cinnamomum camphora & Edens Garden, San Clemente, CA, USA \\
\hline Catnip & Nepeta cataria & Dr. Adorable Inc., Chicago, IL, USA \\
\hline Cedar & Juniperus virginiana & Puritan's Pride, Oakdale, NY, USA \\
\hline Chamomile & Anthemis nobilis & Edens Garden, San Clemente, CA, USA \\
\hline Cinnamon & Cinnamomum cassia & Edens Garden, San Clemente, CA, USA \\
\hline Citronella & Cymbopogon winterianus & Edens Garden, San Clemente, CA, USA \\
\hline Dill & Anethum graveolens & Edens Garden, San Clemente, CA, USA \\
\hline Eucalyptus & Eucalyptus radiata & Nature's Kiss, Moreno Valley, CA, USA \\
\hline Frankincense & Boswellia carterii & Edens Garden, San Clemente, CA, USA \\
\hline Galbanum & Ferula galbaniflua & Nature's Kiss, Moreno Valley, CA, USA \\
\hline Geranium & Pelargonium graveolens & Edens Garden, San Clemente, CA, USA \\
\hline Helichrysum & Helichrysum splendidum & Edens Garden, San Clemente, CA, USA \\
\hline Jasmine & Jasminum grandiflorum & Edens Garden, San Clemente, CA, USA \\
\hline Juniper berry & Juniperus communis & Edens Garden, San Clemente, CA, USA \\
\hline Lavender & Lavandula angustifolia & Edens Garden, San Clemente, CA, USA \\
\hline Lemon & Citrus limon & Puritan's Pride, Oakdale, NY, USA \\
\hline Litsea & Litsea cubeba & Edens Garden, San Clemente, CA, USA \\
\hline Myrtle & Myrtus communis & Edens Garden, San Clemente, CA, USA \\
\hline Niaouli & Melaleuca quinquenervia & Edens Garden, San Clemente, CA, USA \\
\hline Peppermint & Mentha piperita & Puritan's Pride, Oakdale, NY, USA \\
\hline Rosewood & Aniba rosaeodora & Edens Garden, San Clemente, CA, USA \\
\hline Sage & Salvia officinalis & NOW Foods, Bloomingdale, IL, USA \\
\hline Sandalwood & Santalum spicatum & Edens Garden, San Clemente, CA, USA \\
\hline Tagetes & Tagetes bipinnata & Nature's Kiss, Moreno Valley, CA, USA \\
\hline Thyme & Thymus zygis & Edens Garden, San Clemente, CA, USA \\
\hline Verbena & Verbena officinalis & Edens Garden, San Clemente, CA, USA \\
\hline Wintergreen & Gaultheria procumbens & Edens Garden, San Clemente, CA, USA \\
\hline
\end{tabular}

height: $5.25 \mathrm{in} / 133.35 \mathrm{~mm}$ ) with a perforated bottom placed over a plastic Petri dish (100 mm $\times 15 \mathrm{~mm})$, as depicted in Fig. 1. Approximately 30 evenly-distributed holes were punched in the bottom of the cup using thumb tacks and the cups were covered with a piece of fine mesh held in place by a rubber band. The cap of a $1.5 \mathrm{~mL} \mathrm{mi}-$ crocentrifuge tube was glued to the center of a plastic petri dish in order to serve as a well for holding test compounds. Mosquitoes of each strain were anesthetized on ice and transferred to testing cages. Essential oils or acetone were applied at a concentration of $100 \%$ and a volume of $100 \mu \mathrm{L}$ to the microcentrifuge cap and the Petri dish was then placed under the testing cage containing 10 adult female 


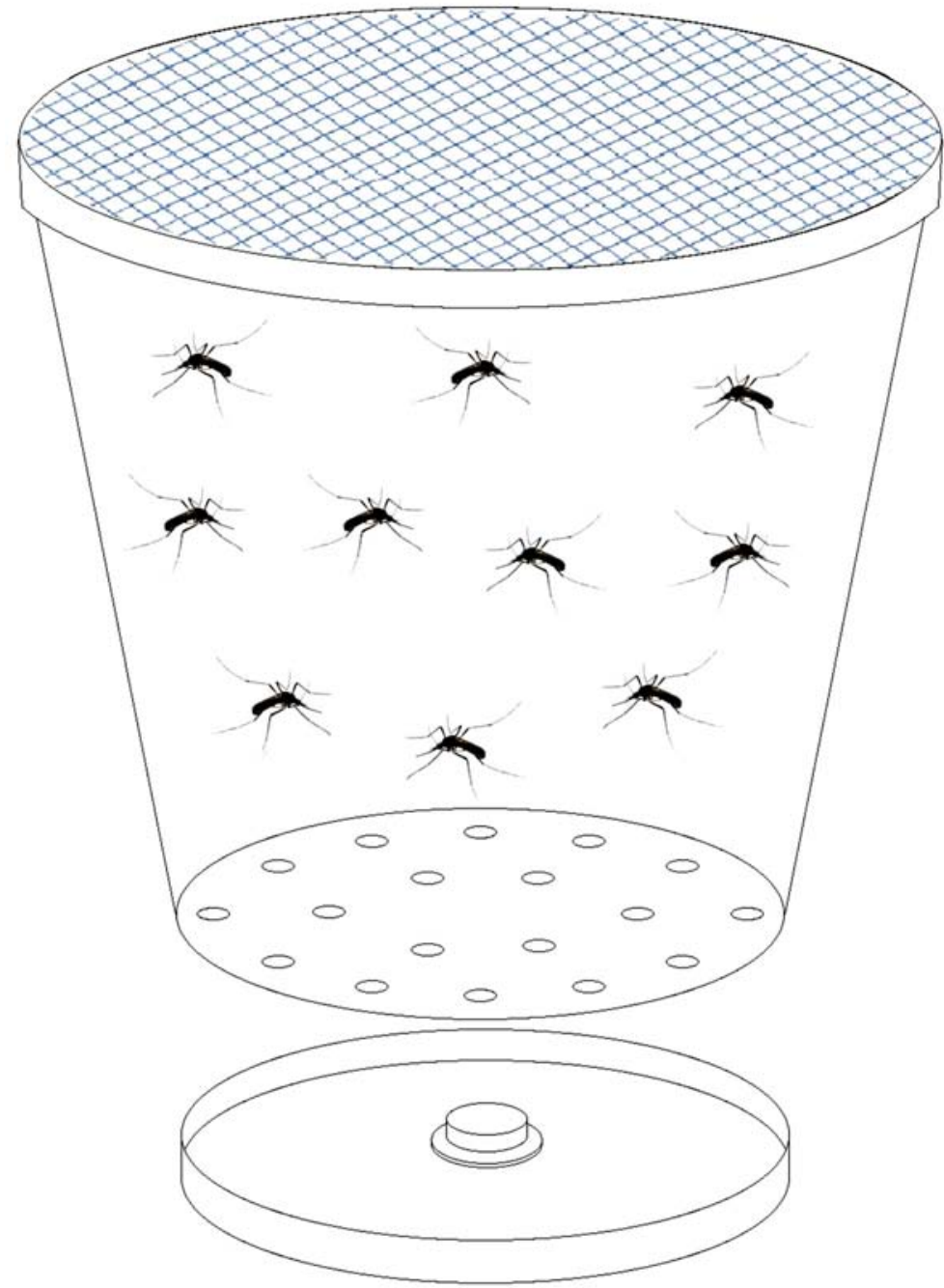

Fig. 1. Diagram of vapor delivery test cage. The testing apparatus consisted of a mesh-covered, white double poly-coated paper soup cup with a perforated bottom placed over a plastic Petri dish modified to hold test compounds.

mosquitoes. Mosquitoes were exposed to the essential oil vapors for $4 \mathrm{~h}$ prior to receiving a topical application on the pronotum of either acetone or deltamethrin. Mosquitoes were then returned to the testing cages, housed in environmental chambers, and supplied with cotton balls soaked in $10 \%$ sucrose until mortality was assessed. Depending on the dose of deltamethrin received, mortality was assessed at either $1 \mathrm{~h}$ or $24 \mathrm{~h}$ following topical application. Follow-up observations of the $1 \mathrm{~h}$ assessments confirmed mortality, rather than knockdown. Abbott's correction (Abbott, 1925) was utilized to control for mosquito mortality in the controls, and if control mortality exceeded 
$20 \%$, data from that test group were not used. Initial screening of essential oils for $1 \mathrm{~h}$ deltamethrin efficacy in the vapor bioassay used 3 to 9 replications with 10 mosquitoes per replicate for each treatment except for the pooled control group which consisted of 33 replications with 10 mosquitoes per replicate. For all subsequent vapor bioassays, 5 to 9 replications with 10 mosquitoes per replicate were used for each treatment or control. Results are reported as mean percent mortality \pm standard deviation for each treatment.

\subsection{Topical bioassays}

Topical bioassays were designed to expose adult mosquitoes to a direct application of essential oils in order to assess their ability to enhance the efficacy of topically-applied deltamethrin. Mosquitoes of each strain received topical applications on the pronotum of $\mathrm{PBO}$, an essential oil, or a vehicle control (acetone) at a volume of $0.2 \mu \mathrm{L}$ and were then transferred into testing cages consisting of white double polycoated paper soup cups with a mesh top to recover for $4 \mathrm{~h}$. Mosquitoes subsequently received topical applications of deltamethrin or acetone and were returned to the testing cages, housed in environmental chambers, and supplied with cotton balls soaked in $10 \%$ sucrose until mortality was assessed. Mortality was assessed at either 1 $\mathrm{h}$ or $24 \mathrm{~h}$ following deltamethrin or vehicle treatment, based on the dose used. Follow-up observations of the $1 \mathrm{~h}$ assessments confirmed mortality, rather than knockdown. Abbot's correction (Abbott, 1925) was utilized to control for mosquito mortality in the controls, and if control mortality exceeded $20 \%$, data from that test group were not used. For all topical bioassays, 5 to 9 replications with 10 mosquitoes per replicate were used for each treatment. Results are reported as mean percent mortality \pm standard deviation for each treatment.

\subsection{Detoxification enzyme activity assays}

Mosquitoes of each strain were cold anesthetized prior to treatment. Mosquitoes receiving a vapor exposure were transferred to testing cages and exposed to either acetone or essential oil vapors $(100 \mu \mathrm{L})$ for $4 \mathrm{~h}$, as described for the vapor bioassay. Mosquitoes receiving topical exposure were treated with acetone, PBO, or an essential oil and then allowed to recover in testing cages for $4 \mathrm{~h}$, as described for 
the topical bioassay. After the $4 \mathrm{~h}$ exposure period, mosquitoes were cold anesthetized, transferred to microcentrifuge tubes, and then flash-frozen in liquid nitrogen and stored at $-80{ }^{\circ} \mathrm{C}$ until used for detoxification enzyme activity assays. Measurements for all enzyme activity assays were conducted using a SpectraMax i3x multimode microplate reader (Molecular Devices, Inc., Sunnyvale, CA). Total protein in each sample preparation was determined using the bicinchoninic acid assay with bovine serum albumin as a standard and measurements performed at $560 \mathrm{~nm}$. Six to nine replications of 10 mosquitoes were used per treatment and each replicate was loaded onto the microplate in triplicate.

\subsubsection{Cytochrome P450 activity}

Cytochrome P450 activity of adult mosquitoes was determined according to the method of Anderson and Zhu (2004) using 7-EC as a substrate, except that samples were first processed using a microsome isolation kit (ab206995) obtained from Abcam (Cambridge, United Kingdom) in order to improve detection of enzyme activity. Each sample of 10 frozen mosquitoes was processed according to manufacturer instructions and isolated microsomes were resuspended in $150 \mu \mathrm{L}$ of the provided storage buffer. Eighty microliters of a mixture containing $50 \mathrm{mM} 7-\mathrm{EC}$ and $62.5 \mathrm{mM}$ reduced $\beta-\mathrm{NADPH}$ were added to microplate wells that contained either $20 \mu \mathrm{L}$ of the isolated microsome preparation, or $20 \mu \mathrm{L}$ of the storage buffer alone as a blank control. The microplate was incubated for $30 \mathrm{~min}$ at $30^{\circ} \mathrm{C}$ while shaking at $400 \mathrm{rpm}$, then $10 \mu \mathrm{L}$ of $100 \mathrm{mM}$ oxidized glutathione and $1.0 \mathrm{U}$ glutathione reductase were added to each microplate well containing the reaction mixture and incubated for $15 \mathrm{~min}$ at $37^{\circ} \mathrm{C}$. The reaction was stopped using $120 \mu \mathrm{L}$ of $50 \%(\mathrm{v} / \mathrm{v})$ acetonitrile in $50 \mathrm{mM}$ TRIZMA-base buffer $(\mathrm{pH}$ 10). Relative fluorescence units were measured at $465 \mathrm{~nm}$ while exciting at $390 \mathrm{~nm}$ and 7-EC-O-deethylation activity was determined using an umbelliferone standard curve. Results are reported as mean relative fluorescence (relative fluorescent units (RFU)/mg of total protein) \pm standard deviation for each treatment.

\subsubsection{General esterase activity}

General esterase activity of adult mosquitoes was determined according to the method described by Zhu and Gao (Zhu and Gao, 1998) using $\alpha-N A$ as the substrate. Each sample of 10 frozen mosquitoes 
was homogenized in $500 \mu \mathrm{L}$ of ice-cold $0.1 \mathrm{M}$ phosphate buffer $(\mathrm{pH}$ 7.0) containing $0.3 \%(\mathrm{v} / \mathrm{v})$ Triton $\mathrm{X}-100$. Homogenates were centrifuged at $10,000 \times g$ for $10 \mathrm{~min}$ at $4{ }^{\circ} \mathrm{C}$ and then the supernatants were used as the enzyme source for measuring both general esterase activity and glutathione S-transferase activity. Aliquots of $15 \mu \mathrm{L}$ of supernatant or buffer alone as a blank control were added to microplate wells along with $135 \mu \mathrm{L}$ of $0.3 \mathrm{mM} \alpha-\mathrm{NA}$, then incubated for $30 \mathrm{~min}$ at $37^{\circ} \mathrm{C}$. Following incubation, $50 \mu \mathrm{L}$ of fast blue B in SDS solution were added to each well to stop the reaction and color was allowed to develop for $15 \mathrm{~min}$ at room temperature. The absorbance was read at $600 \mathrm{~nm}$ and the amount of hydrolytic product for each sample was determined using an $\alpha$-naphthol standard curve. Results are reported as mean specific activity ( $\mathrm{nmol} / \mathrm{min} / \mathrm{mg}$ of total protein) \pm standard deviation for each treatment.

\subsubsection{Glutathione S-transferase activity}

Glutathione $S$-transferase (GST) activity of adult mosquitoes was determined according to Zhu et al. (Zhu et al., 2000) using CDNB as the substrate. Aliquots of $20 \mu \mathrm{L}$ of homogenized mosquito supernatant or buffer alone as a blank control were added to microplate wells along with $180 \mu \mathrm{L}$ of solution containing $10 \mathrm{mM}$ glutathione and $150 \mathrm{mM}$ CDNB. The change in absorbance was immediately recorded at $340 \mathrm{~nm}$ for $12 \mathrm{~min}$ at $1 \mathrm{~min}$ intervals. Results are reported as mean specific activity ( $\mathrm{nmol} / \mathrm{min} / \mathrm{mg}$ of total protein) \pm standard deviation for each treatment.

\subsection{Statistical analysis}

All calculations and statistical analyses were carried out using GraphPad Prism 7 (GraphPad Software, Inc., La Jolla, CA). For the initial screen of essential oils, differences in mortality due to treatment were statistically compared to untreated controls using a one-way analysis of variance (ANOVA) followed by Dunnett's multiple comparison test (Zar, 2007). For all other assays, differences in mortality or enzyme activity based on mosquito strain and treatment were statistically compared to untreated controls using a two-way ANOVA followed by Dunnett's multiple comparison test (Zar, 2007). All statistical tests were carried out at a significance level $(\alpha)$ of 0.05 . 


\section{Results}

\subsection{Vapor bioassays}

In order to identify potential synergists of insecticidal activity that could be delivered as a vapor, 31 essential oils, DEET, and an acetone control were initially screened in 3 to 5 days old female PR mosquitoes using the vapor bioassay for enhancement of deltamethrin efficacy at $1 \mathrm{~h}$ (Table 2). None of the essential oils or DEET were observed to cause mortality when administered alone. Deltamethrin efficacy was significantly increased following exposure to cinnamon (Cinnamomum cassia), sage (Salvia officinalis), and tagetes (Tagetes bipinnata) oils. Deltamethrin efficacy was significantly decreased following exposure to amyris (Amyris balsamifera). Amyris, cinnamon, sage, and tagetes oils were selected for additional testing in both vapor and topical bioassays, as well as for assessment of detoxification enzyme activity. The results of the vapor bioassay for enhancement of deltamethrin efficacy at $1 \mathrm{~h}$ and $24 \mathrm{~h}$ in 3 to 5 days old female Rock and PR mosquitoes are presented in Fig. 2. In the vapor bioassay, deltamethrin efficacy after $1 \mathrm{~h}$ was significantly increased in female Rock mosquitoes following exposure to sage $(+40.63 \%$; $P=.0275)$ and tagetes (+42.51\%; $P=.0298)$, but no significant change was detected following exposure to amyris $(-4.17 \% ; P=.9935)$ or cinnamon (+6.25\%; $P=.9804)$. In female PR mosquitoes, vapor delivery significantly increased deltamethrin efficacy at $1 \mathrm{~h}$ following exposure to cinnamon (+42.85\%; $P=.0467)$, sage $(+42.85 \% ; P=.0467)$, and tagetes (+60.70\%; $P=.0025)$, but significantly decreased activity following exposure to amyris $(-52.37 \% ; P=.0036)$. Deltamethrin efficacy at $24 \mathrm{~h}$ in female Rock mosquitoes was significantly increased following exposure to sage $(+40.00 \% ; P=.0101)$ and tagetes $(+32.50 \%$; $P=.0275)$, but no significant change was detected following exposure to amyris $(-4.44 \% ; P=.9857)$ or cinnamon $(+26.66 \% ; P=.1311)$. In female PR mosquitoes, vapor delivery significantly increased deltamethrin efficacy at $24 \mathrm{~h}$ following exposure to cinnamon $(+60.00 \% ; P$ $<.0001)$, sage $(+40.00 \% ; P=.0163)$, and tagetes $(+48.00 \% ; P=.0030)$, but no significant change in activity was detected following exposure to amyris $(-13.33 \% ; P=.6848)$. 
Table 2. Results of initial screening of essential oils using vapor assay for enhancement of 1 $\mathrm{h}$ deltamethrin toxicity in pyrethroid-resistant, adult female mosquitoes.

\begin{tabular}{|c|c|c|c|c|}
\hline Treatment & $\begin{array}{c}\text { Average } \\
\% \text { mortality }\end{array}$ & $\begin{array}{l}\text { Standard } \\
\text { Deviation }\end{array}$ & $P$ value & $n$ \\
\hline Amyris balsamifera & 22.22 & 12.02 & .0492 & 9 \\
\hline Ocimum basilicum & 55.00 & 10.49 & .9020 & 6 \\
\hline Piper nigrum & 56.67 & 21.60 & .7526 & 6 \\
\hline Melaleuca cajuputi & 58.33 & 7.53 & .5571 & 6 \\
\hline Cinnamomum camphora & 53.33 & 5.77 & .9987 & 3 \\
\hline Nepeta cataria & 46.67 & 16.33 & .9994 & 6 \\
\hline Juniperus virginiana & 40.00 & 17.32 & .9998 & 3 \\
\hline Anthemis nobilis & 50.00 & 20.98 & .9988 & 6 \\
\hline Cinnamomum cassia & 66.67 & 15.06 & .0310 & 6 \\
\hline Cymbopogon winterianus & 40.00 & 10.00 & .9998 & 3 \\
\hline $\mathrm{N}, \mathrm{N}$-Diethyl-metatoluamide & 56.67 & 15.28 & .9848 & 3 \\
\hline Anethum graveolens & 53.33 & 15.28 & .9987 & 3 \\
\hline Eucalyptus radiata & 30.00 & 10.00 & .9946 & 3 \\
\hline Boswellia carterii & 46.67 & 11.55 & .9996 & 3 \\
\hline Ferula galbaniflua & 51.67 & 21.37 & .9936 & 6 \\
\hline Pelargonium graveolens & 41.67 & 23.17 & $>.9999$ & 6 \\
\hline Helichrysum splendidum & 53.33 & 11.55 & .9987 & 3 \\
\hline Jasminum grandiflorum & 41.67 & 27.14 & $>.9999$ & 6 \\
\hline Juniperus communis & 40.00 & 22.80 & .9997 & 6 \\
\hline Lavandula angustifolia & 46.67 & 16.33 & .9994 & 6 \\
\hline Citrus limon & 36.67 & 5.77 & .9995 & 3 \\
\hline Litsea cubeba & 40.00 & 10.95 & .9997 & 6 \\
\hline Myrtus communis & 36.67 & 5.77 & .9995 & 3 \\
\hline Melaleuca quinquenervia & 50.00 & 10.00 & .9992 & 3 \\
\hline Mentha piperita & 43.33 & 5.77 & $>.9999$ & 3 \\
\hline Aniba rosaeodora & 48.33 & 13.29 & .9991 & 6 \\
\hline Salvia officinalis & 66.67 & 12.11 & .0310 & 6 \\
\hline Santalum spicatum & 40.00 & 20.00 & .9997 & 6 \\
\hline Tagetes bipinnata & 75.00 & 12.25 & .0004 & 6 \\
\hline Thymus zygis & 41.67 & 13.29 & $>.9999$ & 6 \\
\hline Verbena officinalis & 30.00 & 10.00 & .9946 & 3 \\
\hline Gaultheria procumbens & 50.00 & 26.83 & .9988 & 6 \\
\hline
\end{tabular}

Bold text indicates that the means are significantly different from the acetone control according to a two-way ANOVA and Dunnett's multiple comparison test where $\mathrm{P}<.05$ was considered significant. 
A.
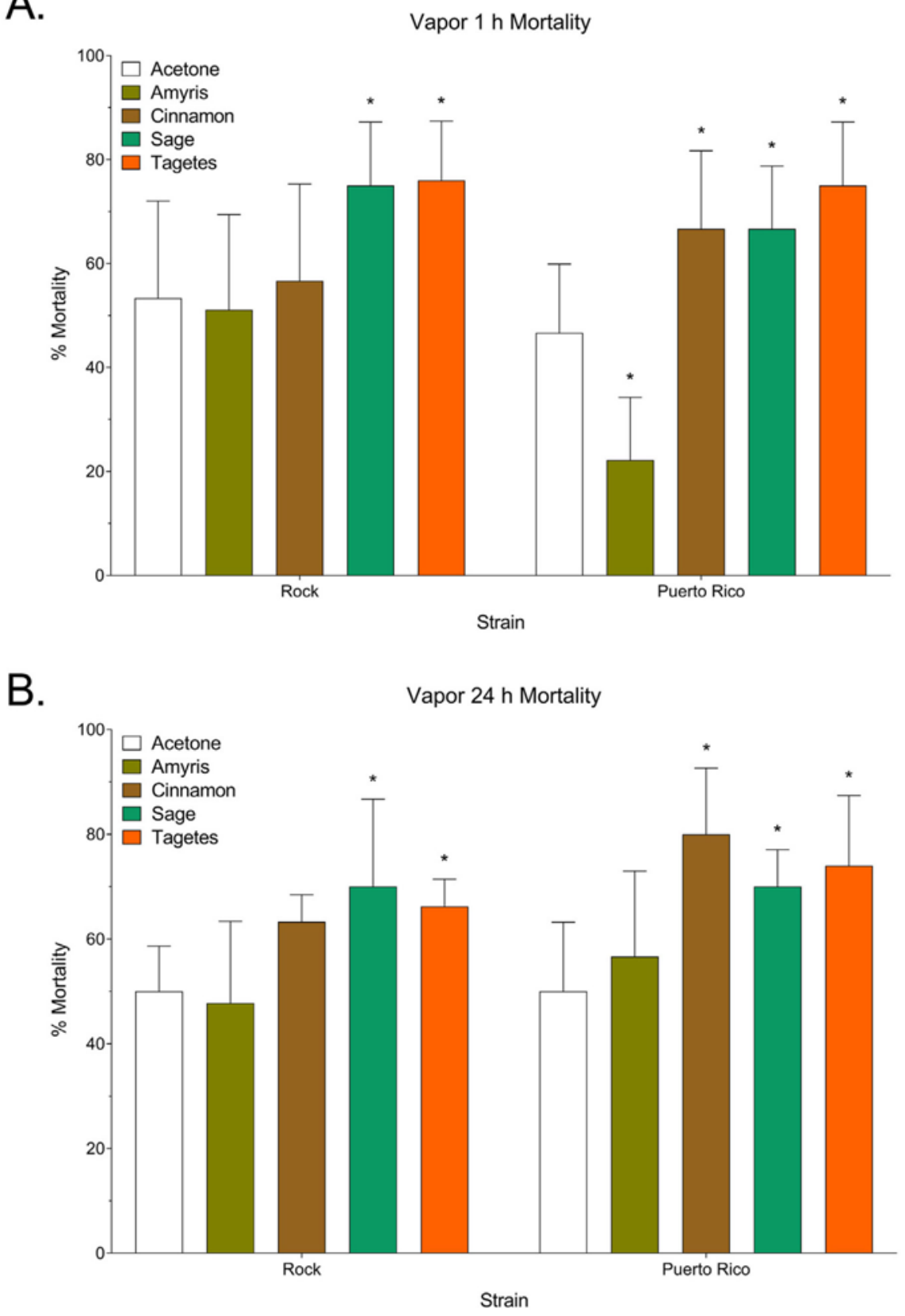

Fig. 2. Effect of essential oils delivered as vapor on deltamethrin toxicity in pyrethroid-susceptible (Rock) and pyrethroid-resistant (Puerto Rico) strains of adult female mosquitoes at: A. $1 \mathrm{~h}$ and B. $24 \mathrm{~h}$ following topical application of a median lethal dose of deltamethrin. Bars represent mean percent mortality \pm standard deviation. Asterisks denote that the means are significantly different from the respective acetone control according to a two-way ANOVA and Dunnett's multiple comparison test where $P<.05$ was considered significant. 


\subsection{Contact bioassays}

In order to assess the efficacy of the selected essential oils at enhancing insecticidal activity via topical exposure, amyris, cinnamon, sage, and tagetes oils were tested along with the cytochrome P450 inhibitor PBO and an acetone control in the topical bioassay for enhancement of deltamethrin efficacy at $1 \mathrm{~h}$ and $24 \mathrm{~h}$ in 3 to 5 days old female Rock and PR mosquitoes. The results of this work are presented in Fig. 3. Deltamethrin efficacy after $1 \mathrm{~h}$ was significantly increased in female Rock mosquitoes following exposure to PBO (+35.29\%; $P=.0026)$, but no significant change was detected following exposure to amyris $(-15.69 \% ; P=.2621)$, cinnamon $(+14.70 \% ; P=.4230)$, sage $(-8.82 \% ; P=.8338)$, or tagetes $(+2.94 \% ; P=.9982)$. Deltamethrin efficacy after $1 \mathrm{~h}$ was also significantly increased in female PR mosquitoes following exposure to PBO $(+60.22 \% ; P<.0001)$, but no significant change was detected following exposure to amyris $(-11.36 \%$; $P=.7709)$, cinnamon (+9.09\%; $P=.8877)$, sage $(+2.27 \% ; P=.9997)$, or tagetes $(-7.95 \% ; P=.9310)$. Deltamethrin efficacy after $24 \mathrm{~h}$ was significantly increased in female Rock mosquitoes following exposure to PBO (+72.50\%; $P<.0001)$ and cinnamon $(+42.51 \% ; P=.0186)$, but no significant change was detected following exposure to amyris $(+12.50 \% ; P=.7956)$, sage (+23.76\%; $P=.3405)$, or tagetes $(+25.00 \%$; $P=.2021$ ). Similar to the results of the $1 \mathrm{~h}$ bioassay, deltamethrin efficacy after $24 \mathrm{~h}$ was significantly increased in female PR mosquitoes following exposure to PBO $(+72.50 \% ; P<.0001)$, but no significant change was detected following exposure to amyris $(+22.50 \%$; $P=.2886)$, cinnamon $(+27.50 \% ; P=.2147)$, sage $(+35.01 \% ; P=.0707)$, or tagetes $(+20.00 \% ; P=.5041)$.

\subsection{Detoxification enzyme activity assays}

In order to investigate the mechanism by which amyris, cinnamon, sage, and tagetes oils increase or decrease deltamethrin efficacy, assays were conducted to measure the impact that exposure to these oils has on cytochrome P450, general esterase, and GST activity in 3 to 5 days old female Rock and PR mosquitoes. Mosquitoes were either exposed to one of the four oils or an acetone control using vapor delivery or exposed to one of the four oils, acetone, or PBO using topical delivery. 
A.

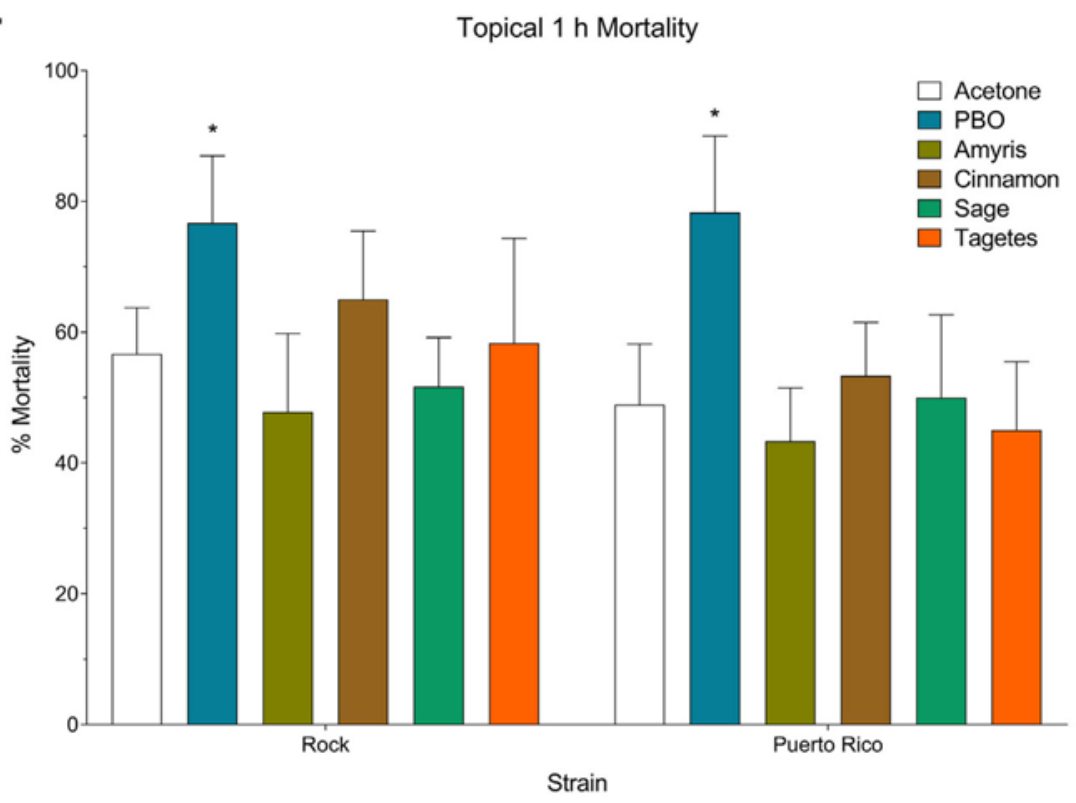

B.

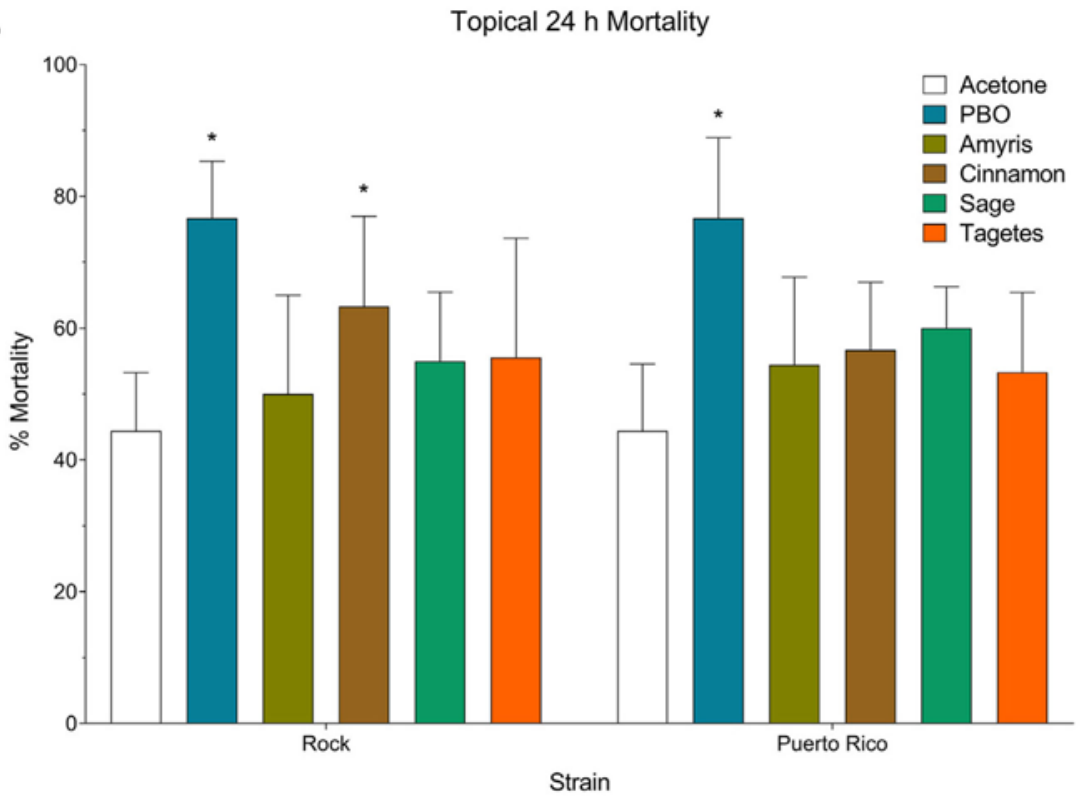

Fig. 3. Effect of essential oils delivered topically on deltamethrin toxicity in pyrethroid-susceptible (Rock) and pyrethroid-resistant (Puerto Rico) strains of adult female mosquitoes at: A. $1 \mathrm{~h}$ and B. $24 \mathrm{~h}$ following topical application of a median lethal dose of deltamethrin. Bars represent mean percent mortality \pm standard deviation. Asterisks denote that the means are significantly different from the respective acetone control according to a two-way ANOVA and Dunnett's multiple comparison test where $P<.05$ was considered significant. 


\subsection{Cytochrome $P 450$ enzyme activity}

The results of the P450 activity assays following either vapor or topical delivery are presented in Fig. 4. P450 activity was significantly decreased in female Rock mosquitoes following vapor exposure to sage $(-36.40 \% ; P=.0369)$ and tagetes $(-36.05 \% ; P=.0392)$, but no significant change was detected following exposure to cinnamon $(-11.62 \%$; $P=.8129$ ) and a significant increase was observed following exposure to amyris (+46.99\%; $P=.0046)$. In female PR mosquitoes, P450 activity was significantly decreased following vapor exposure to cinnamon $(-28.55 \% ; P=.0021)$, sage $(-38.60 \% ; P<.0001)$, and tagetes $(-33.96 \% ; P=.0002)$, but significantly increased following exposure to amyris (+33.61\%; $P=.0003)$. P450 activity was significantly decreased in female Rock mosquitoes following topical exposure to PBO (-73.52\%; $P<.0001)$, but no significant change was detected following exposure to cinnamon $(-16.42 \% ; P=.7196)$, sage $(-23.68 \% ; P=.3921)$, or tagetes $(-36.25 \% ; P=.0794)$ and a significant increase was observed following exposure to amyris (+47.34\%; $P=.0123)$. In female PR mosquitoes, P450 activity was significantly decreased following topical exposure to PBO $(-58.24 \% ; P<.0001)$, cinnamon $(-30.60 \% ; P=.0127)$, sage $(-31.85 \% ; P=.0089)$, and tagetes $(-36.45 \% ; P=.0022)$, but no significant change was observed following exposure to amyris $(-13.31 \%$; $P=.5283)$.

\subsubsection{General esterase activity}

The results of the general esterase activity assays following either vapor or topical delivery are presented in Fig. 5. No significant change in esterase activity was observed in female Rock mosquitoes following vapor exposure to amyris $(+3.50 \% ; P=.7365)$, cinnamon $(+1.66 \%$; $P=.9739)$, sage $(+6.11 \% ; P=.2808)$, or tagetes $(-6.00 \% ; P=.2953)$. Similarly, no significant change in esterase activity was observed in female PR mosquitoes following vapor exposure to amyris $(+4.82 \%$; $P=.5022)$, cinnamon $(-1.96 \% ; P=.9560)$, sage $(-9.84 \% ; P=.0705)$, or tagetes $(-2.33 \% ; P=.9230)$. Esterase activity was significantly increased in female Rock mosquitoes following topical exposure to amyris (+22.22\%; $P=.0081)$, but no significant change was detected following exposure to $\mathrm{PBO}(+3.24 \% ; P=.9861)$, cinnamon $(+10.55 \% ; P=.3980)$, sage $(+13.13 \% ; P=.2073)$, or tagetes $(+13.91 \% ; P=.1655)$. Similarly, esterase activity was significantly increased in female PR mosquitoes 

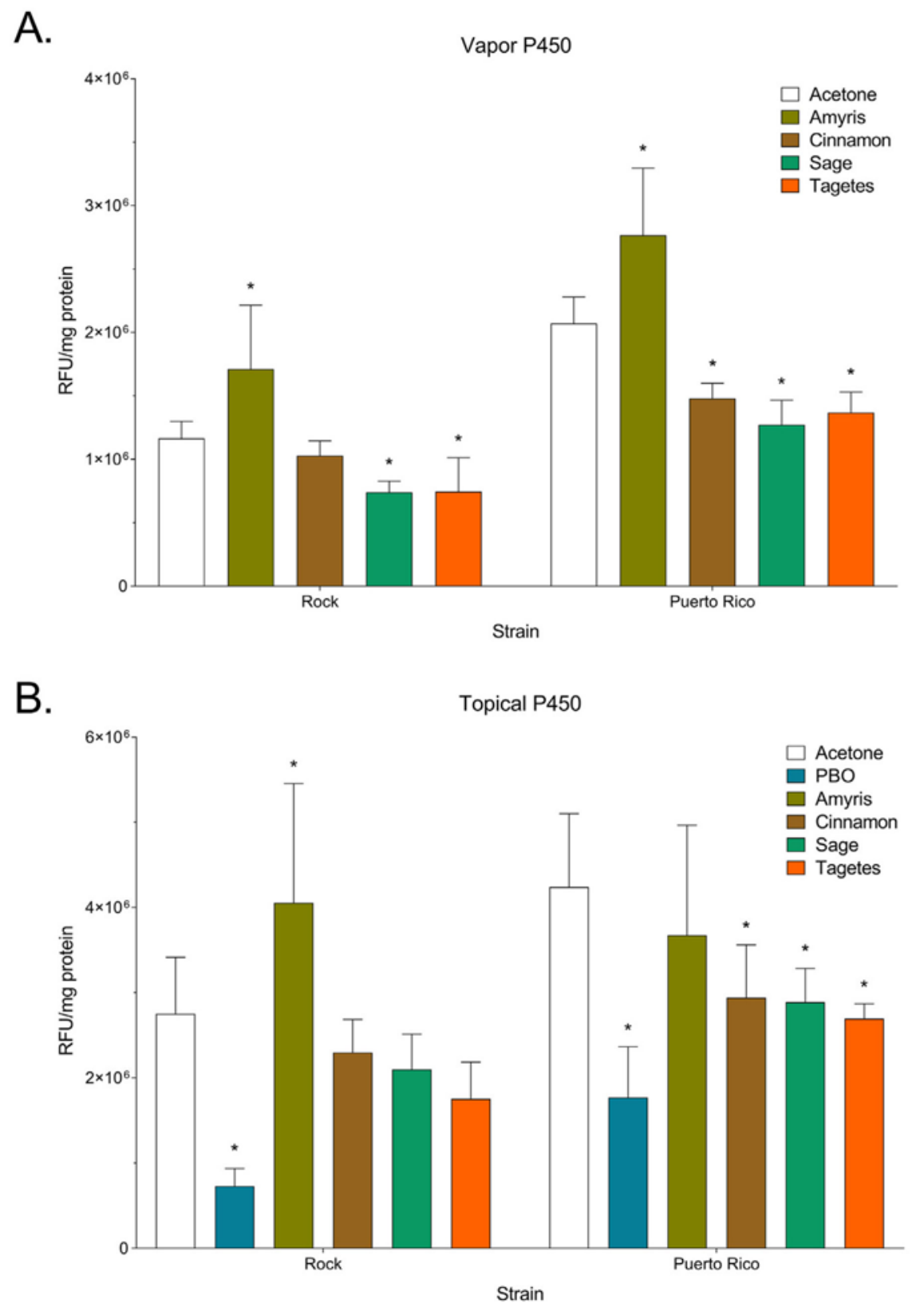

Fig. 4. Effect of A. essential oils delivered as a vapor and B. essential oils or the cytochrome P450 inhibitor piperonyl butoxide (PBO) delivered topically on cytochrome P450 activity in pyrethroid-susceptible (Rock) and pyrethroid-resistant (Puerto Rico) adult female mosquito strains. Bars represent mean relative fluorescence (relative fluorescent units (RFU)/mg of total protein) \pm standard deviation. Asterisks denote that the means are significantly different from the respective acetone control according to a two-way ANOVA and Dunnett's multiple comparison test where $P<$ .05 was considered significant. 
A.

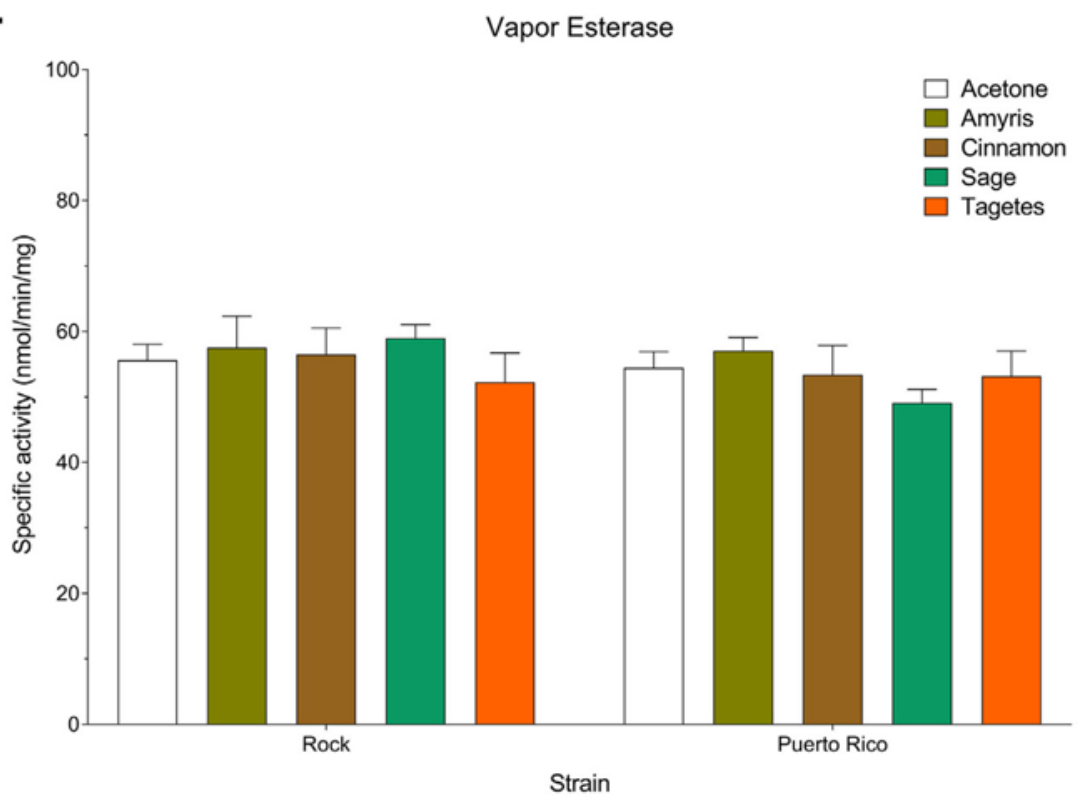

B.

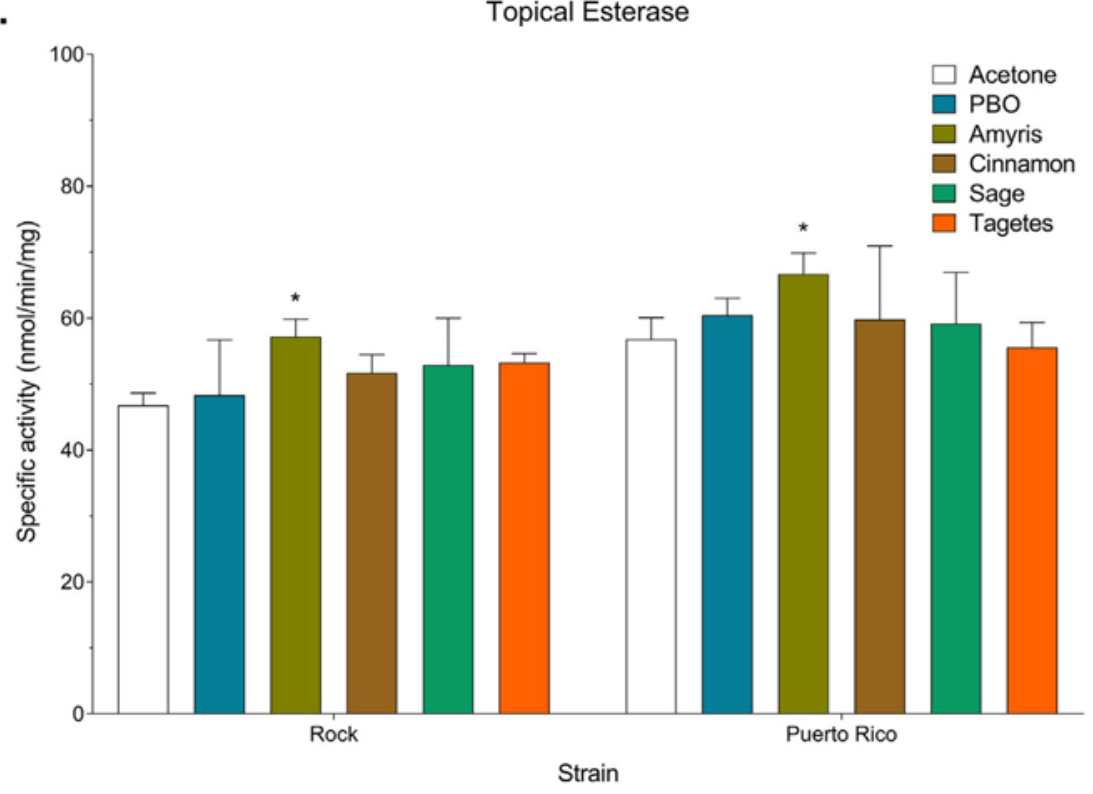

Fig. 5. Effect of A. essential oils delivered as a vapor and B. essential oils or the cytochrome P450 inhibitor piperonyl butoxide (PBO) delivered topically on general esterase activity in pyrethroid-susceptible (Rock) and pyrethroid-resistant (Puerto Rico) adult female mosquito strains. Bars represent mean specific activity ( $\mathrm{nmol} / \mathrm{min} / \mathrm{mg}$ of total protein) \pm standard deviation. Asterisks denote that the means are significantly different from the respective acetone control according to a two-way ANOVA and Dunnett's multiple comparison test where $P<.05$ was considered significant. 
following topical exposure to amyris ( $+17.47 \% ; P=.0124)$, but no significant change was detected following exposure to PBO (+6.46\%; $P=.6696)$, cinnamon ( $+5.31 \% ; P=.8082)$, sage $(+4.24 \% ; P=.9098)$, or tagetes $(-2.13 \% ; P=.9950)$.

\subsubsection{Glutathione S-transferase activity}

The results of the GST activity assays following either vapor or topical delivery are presented in Fig. 6. No significant change in GST activity was observed in female Rock mosquitoes following vapor exposure to amyris $(+16.95 \% ; P=.1796)$, cinnamon $(+8.62 \% ; P=.6949)$, sage $(+2.36 \% ; P=.9958)$, or tagetes $(+8.62 \% ; P=.6952)$. Similarly, no significant change in GST activity was observed in female PR mosquitoes following vapor exposure to amyris $(+3.45 \% ; P=.9624)$, cinnamon (+6.28\%; $P=.7651)$, sage $(-0.66 \% ; P=.9999)$, or tagetes (+6.63\%; $P=.7612$ ). No significant change in GST activity was observed in female Rock mosquitoes following topical exposure to PBO (+7.28\%; $P=.8851)$, amyris $(-3.10 \% ; P=.9965)$, cinnamon $(+20.29 \% ; P=.1072)$, sage $(+1.01 \% ; P=.9999)$, or tagetes $(+5.07 \% ; P=.9714)$. Similarly, no significant change in GST activity was observed in female PR mosquitoes following topical exposure to PBO $(-6.67 \% ; P=.7794)$, amyris $(-0.12 \% ; P>.9999)$, cinnamon $(-16.05 \% ; P=.1023)$, sage $(-10.13 \%$; $P=.47075)$, or tagetes $(-11.55 \% ; P=.3035)$.

\section{Discussion}

In previous studies investigating the ability of topically-applied, plantderived essential oils to enhance pyrethroid efficacy in mosquitoes, the results have been varied (Belzile et al., 2000; Pavela, 2008; Joffe et al., 2012; Tong and Bloomquist, 2013; Faraone et al., 2015; Tak and Isman, 2015; Tak et al., 2015; Gross et al., 2017; Norris et al., 2018). In this study, which was designed to identify potential synergists of pyrethroid efficacy that could be delivered as a vapor, only 3 oils out of an initial screen of 31 essential oils and DEET were found to enhance the $1 \mathrm{~h}$ efficacy of the pyrethroid insecticide deltamethrin against female mosquitoes of the resistant PR strain when tested in the vapor bioassay (cinnamon, sage, and tagetes oils), while 1 oil actually had the opposite effect and decreased efficacy (amyris oil). At $24 \mathrm{~h}$, cinnamon, sage, and tagetes oils all continued to enhance deltamethrin efficacy, 
A.

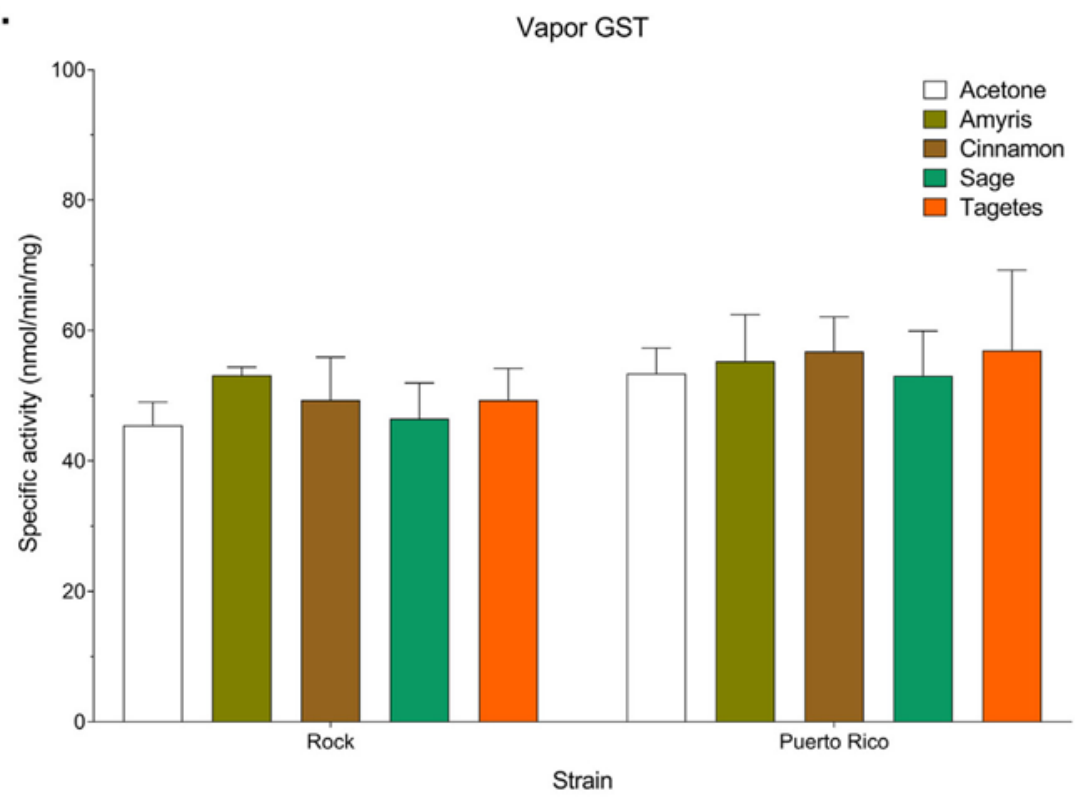

B.

Topical GST

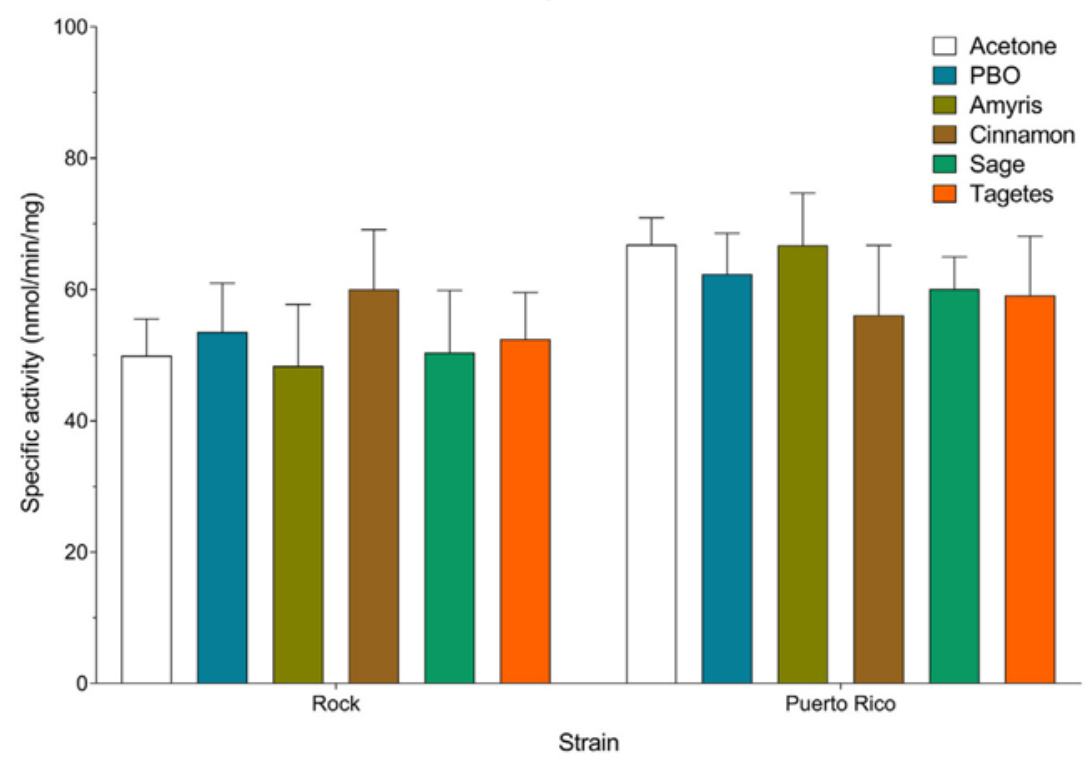

Fig. 6. Effect of A. essential oils delivered as a vapor and B. essential oils or the cytochrome P450 inhibitor piperonyl butoxide (PBO) delivered topically on glutathione S-transferase (GST) activity in pyrethroid-susceptible (Rock) and pyrethroidresistant (Puerto Rico) adult female mosquito strains. Bars represent mean specific activity ( $\mathrm{nmol} / \mathrm{min} / \mathrm{mg}$ of total protein) \pm standard deviation. Asterisks denote that the means are significantly different from the respective acetone control according to a two-way ANOVA and Dunnett's multiple comparison test where $P<.05$ was considered significant. 
but amyris oil no longer decreased efficacy. When tested against females of the susceptible Rock strain in the vapor bioassay, sage and tagetes oils both demonstrated a similar enhancement of deltamethrin efficacy at $1 \mathrm{~h}$ and at $24 \mathrm{~h}$, but no significant effect of amyris or cinnamon was observed at either exposure time.

Overall, sage and tagetes oils appeared to be the most consistent across strains and exposure times tested for the vapor bioassay, while exposure to cinnamon oil only produced an effect in the resistant strain. These findings align well with the enzyme assays of P450 activity following vapor exposure, which showed that P450 activity decreased in both strains following exposure to sage and tagetes oils, whereas exposure to cinnamon oil only produced a decrease in activity in the resistant strain. This result suggests that these oils are inhibiting or otherwise interfering with mosquito P450 activity and raises questions about the mode of action for cinnamon and how it differs from that of sage and tagetes to produce such a strain-specific effect. The lack of change in either esterase or GST activity resulting from treatment with these essential oils suggests that the enhanced efficacy that is observed in combination with deltamethrin is not due to inhibition or disruption of either of these detoxification enzymes. Vapor exposure to amyris oil, which displayed such a pronounced effect at $1 \mathrm{~h}$ in the resistant strain, did not produce the same result at $24 \mathrm{~h}$, nor did it have an effect on the susceptible strain at either exposure time. These findings are somewhat incongruent with the observation that amyris treatment in the vapor assay increased P450 activity in both strains, calling into question the relevance of P450 activity in the observed change in efficacy of deltamethrin. Given that amyris had no effect on either esterase or GST activity, it is possible that amyris is producing its effect by some other mechanism than altered P450 activity, or that increased P450 activity is only partially contributing to this effect. The lack of effect of amyris treatment on $1 \mathrm{~h}$ mortality in Rock mosquitoes could be due to experimental error, possibly the result of artificially high mortality due to mishandling or inadequate vapor exposure. It is also possible that the change in P450 activity in Rock, although statistically significant, was simply not biologically relevant. Finally, it should be noted that the measurements of P450, esterase, and GST activity represent a single point in time, following 4 $\mathrm{h}$ of exposure, and are likely more relevant to the $1 \mathrm{~h}$ mortality measurements than to the $24 \mathrm{~h}$ mortality measurements. 
The selected essential oils were far less effective with the topical assays. The standard synergist PBO, which served as a positive control for P450 inhibition in the topical assays, consistently produced an effect on both deltamethrin efficacy and P450 activity, as was expected. This differs somewhat from the findings of Gross et al., who described only marginal effects of PBO with topical toxicity assays using permethrin (Gross et al., 2017), but this is likely a function of the differences in experimental design, as the authors of that study co-applied essential oils with permethrin and tested only susceptible strains of both Aedes aegypti and Anopheles gambiae mosquitoes. In this study, PBO significantly enhanced deltamethrin efficacy in both strains and at both exposure times, in addition to significantly decreasing P450 activity in both strains. No effects of PBO were observed on the activity of either esterase or GST. PBO was not used as a control in the vapor assay, as preliminary studies demonstrated no effect of PBO in the vapor assay, most likely due to it being less volatile than the essential oils. The only essential oil to either increase or decrease deltamethrin efficacy in topical assays was cinnamon oil, which increased $24 \mathrm{~h}$ efficacy only in the susceptible strain. Interestingly enough, despite not having any significant effect on deltamethrin efficacy in the resistant strain when delivered via topical exposure, cinnamon, sage, and tagetes oils all were observed to significantly reduce $\mathrm{P} 450$ activity in the resistant strain. One possible explanation is that topical application of these essential oils prior to topical application of deltamethrin disrupts or alters the ability of deltamethrin to penetrate the cuticle to the extent that it would otherwise, which would result in lower than expected mortality. It is also possible that these changes in P450 activity, while statistically significant, are simply not biologically relevant in the resistant strain. Furthermore, amyris oil delivered via topical exposure significantly increased P450 activity in the susceptible strain, and also significantly increased esterase activity in both strains. These findings represent the effects produced by the selected concentration used to test each essential oil when applied topically, and consequently do not provide insight into the concentration-dependent effects of these oils. An important goal of future studies related to this work would be to determine whether or not these effects are dependent upon this specific treatment regimen, as well as the relationship between concentration and observed effect. While the results presented here certainly invite a multitude of questions 
about the nature of these essential oils and how they are interacting with mosquito physiology to increase or decrease the efficacy of deltamethrin, the evidence strongly suggests that interactions with cytochrome P450 activity in mosquitoes are a contributing factor to the observed efficacy changes. This is not especially surprising given the important role that $\mathrm{P} 450$ s play in the detoxification of insecticides (Bergé et al., 1998) and the fact that the most common commercial synergist, $\mathrm{PBO}$, is derived from botanical compounds that were first identified as components of sesame oil (Tozzi, 1999). Indeed, these findings reinforce the value of investigating natural sources such as botanicals to find inspiration for the development of novel insecticides, repellents, and even synergists.

This initial work has proven quite successful at achieving one of the underlying aims of this study, which was to demonstrate an approach for testing an alternate delivery method for volatile products such as plant essential oils that could be used in conjunction with the growing array of personal protection products that rely on spatial repellents. The approach being used here differs from that of previously reported studies that have tested essential oils as fumigants as it allows exposure to the vapors in an open environment in which air in the testing container may freely circulate with the air in the room. Pilot studies using closed bottle assays resulted in significantly high levels of mortality from exposure to essential oil vapors that did not accurately reflect what would be seen if the product was delivered in the manner of spatial repellents. This initial study did make certain concessions such as pre-treating insects with the essential oils prior to treating them with deltamethrin, as well as using a topical route of exposure for deltamethrin, rather than using vapor exposure of a pyrethroid spatial repellent, in order to reduce variability and offer proof of concept. Future studies will ideally address this approach in a more applied context in order to assess how this knowledge might be applied to existing or future mosquito abatement practices, but that does not mean that this study is without practical merit. Deltamethrin is commonly used in not only residual sprays, but also in long-lasting, insecticide-treated bed nets. The approach demonstrated here could hypothetically be employed to enhance the efficacy against resistant mosquito strains of existing formulations of products that rely on contact exposure with the insect, as opposed to reformulating such products to incorporate a synergist. Essential oils, or their active principal components, could 
potentially be delivered via any number of existing commercial vaporizers, emanators, coils, candles, or other products in combination with residual sprays, long-lasting insecticidal bed nets, or even pyrethroid spatial repellents to enhance insecticidal efficacy.

More work is required, however, in order to further elucidate the relationship between pyrethroid mortality and spatial repellency. Furthermore, given the common practice of employing natural products such as essential oils in vaporizers and other delivery devices for their aromatic appeal and use in alternative medicines, this study emphasizes the need to more fully evaluate such products for not only their ability to increase insecticide efficacy, but also for their ability to decrease it. For example, based on these findings, it is reasonable to hypothesize that employing an amyris oil vaporizer in a room where residual spraying or the use of a treated bed net occurs could reduce the efficacy of such mosquito abatement practices, but further research would be needed to demonstrate this. Future studies based on this work will more thoroughly investigate natural products such as the ones described here for efficacy as synergists of vapor-active insecticides, potentially adding another approach to help limit the negative impact on human and animal health posed by the spread of mosquito-vectored pathogens.

Acknowledgments - The authors would like to thank Justine LaViolette for technical assistance with mosquito colony maintenance, enzyme assays, and graphical design support, as well as William Noundou for assisting with mosquito colony maintenance. This research did not receive any specific grant from funding agencies in the public, commercial, or not-for-profit sectors.

Author contributions - Conceptualization: STO, EJJ, LCR, TDA. Investigation: STO, EJJ, LCR, TDA. Formal Analysis: STO, EJJ, TDA. Original Draft Preparation: STO, EJJ, TDA. Review and Editing: STO, EJJ, LCR, TDA.

Competing interests - The authors declared no competing financial interests.

\section{References}

Abbott, W.S., 1925. A method of computing the effectiveness of an insecticide. J.

Econ. Entomol. 18, 265-267.

Abdel-Mohdy, F.A., Fouda, M.M.G., Rehan, M.F., Aly, A.S., 2008. Repellency of controlled- release treated cotton fabrics based on cypermethrin and prallethrin. Carbohydr. Polym. 73, 92-97. 
Achee, N.L., Bangs, M.J., Farlow, R., Killeen, G.F., Lindsay, S., Logan, J.G., Moore, S.J., Rowland, M., Sweeney, K., Torr, S.J., Zwiebel, L.J., Grieco, J.P., 2012. Spatial repellents: from discovery and development to evidence-based validation. Malar. J. 11, 164.

Anderson, T.D., Zhu, K.Y., 2004. Synergistic and antagonistic effects of atrazine on the toxicity of organophosphorodithioate and organophosphorothioate insecticides to Chironomus tentans (Diptera: Chironomidae). Pestic. Biochem. Physiol. 80, 54-64.

Belzile, A.-S., Majerus, S.L., Podeszfinski, C., Guillet, G., Durst, T., Arnason, J.T., 2000. Dillapiol derivatives as synergists: structure-activity relationship analysis. Pestic. Biochem. Physiol. 66, 33-40.

Bergé, J.B., Feyereisen, R., Amichot, M., 1998. Cytochrome P450 monooxygenases and insecticide resistance in insects. Philos. Trans. R. Soc. Lond. Ser. B Biol. Sci. 353, 1701-1705.

Bibbs, C.S., Xue, R.-D., 2016. OFF! clip-on repellent device with metofluthrin tested on Aedes aegypti (Diptera: Culicidae) for mortality at different time intervals and distances. J. Med. Entomol. 53, 480-483.

Bibbs, C.S., Tsikolia, M., Bloomquist, J.R., Bernier, U.R., Xue, R.-D., Kaufman, P.E., 2018. Vapor toxicity of five volatile pyrethroids against Aedes aegypti, Aedes albopictus, Culex quinquefasciatus, and Anopheles quadrimaculatus (Diptera: Culicidae). Pest Manag. Sci. 74, 2699-2706.

CDC, 2016. Operational Risk Communication and Community Engagement Plan Responding to Local Mosquito-Borne Transmission of Zika Virus, Atlanta, GA.

Dias, C.N., Moraes, D.F.C., 2014. Essential oils and their compounds as Aedes aegypti L. (Diptera: Culicidae) larvicides: review. Parasitol. Res. 113, 565-592.

Faraone, N., Hillier, N.K., Cutler, G.C., 2015. Plant essential oils synergize and antagonize toxicity of different conventional insecticides against Myzus persicae (Hemiptera: Aphididae). PLoS ONE 10, e0127774.

Fauci, A.S., Morens, D.M., 2016. Zika virus in the Americas - yet another arbovirus threat. N. Engl. J. Med. 374, 601-604.

Gross, A.D., Coats, J.R., 2015. Can green chemistry provide effective repellents? In: Insect Repellents Handbook, 2nd edition. pp. 75-90.

Gross, A.D., Norris, E.J., Kimber, M.J., Bartholomay, L.C., Coats, J.R., 2017. Essential oils enhance the toxicity of permethrin against Aedes aegypti and Anopheles gambiae. Med. Vet. Entomol. 31, 55-62.

Gubler, D.J., 2010. The global threat of emergent/re-emergent vector-borne diseases. In: Atkinson, P.W. (Ed.), Vector Biology, Ecology and Control. Springer Netherlands, Dordrecht, pp. 39-62.

Hemingway, J., Ranson, H., 2000. Insecticide resistance in insect vectors of human disease. Annu. Rev. Entomol. 45, 371-391.

Joffe, T., Gunning, R.V., Allen, G.R., Kristensen, M., Alptekin, S., Field, L.M., Moores, G.D., 2012. Investigating the potential of selected natural compounds to increase the potency of pyrethrum against houseflies Musca domestica (Diptera: Muscidae). Pest Manag. Sci. 68, 178-184. 
Matthews, H.B., Casida, J.E., 1970. Properties of housefly microsomal cytochromes in relation to sex, strain, substrate specificity, and apparent inhibition and induction by synergist and insecticide chemicals. Life Sci. 9, 989-1001.

Metcalf, R.L., 1967. Mode of action of insecticide synergists. Annu. Rev. Entomol. 12, 229-256.

Nauen, R., 2007. Insecticide resistance in disease vectors of public health importance. Pest Manag. Sci. 63, 628-633.

Norris, E.J., Coats, J.R., 2017. Current and future repellent technologies: the potential of spatial repellents and their place in mosquito-borne disease control. Int. J. Environ. Res. Public Health 14.

Norris, E.J., Gross, A.D., Dunphy, B.M., Bessette, S., Bartholomay, L., Coats, J.R., 2015. Comparison of the insecticidal characteristics of commercially available plant essential oils against Aedes aegypti and Anopheles gambiae (Diptera: Culicidae). J. Med. Entomol. 52, 993-1002.

Norris, E., Johnson, J., Gross, A., Bartholomay, L., Coats, J., 2018. Plant essential oils enhance diverse pyrethroids against multiple strains of mosquitoes and inhibit detoxification enzyme processes. Insects 9, 132.

Pavela, R., 2008. Acute and synergistic effects of some monoterpenoid essential oil compounds on the house fly (Musca domestica L.). J. Essential Oil Bearing Plants 11, 451-459.

Rapley, L.P., Russell, R.C., Montgomery, B.L., Ritchie, S.A., 2009. The effects of sustained release metofluthrin on the biting, movement, and mortality of Aedes aegypti in a domestic setting. Am. J. Trop. Med. Hyg. 81, 94-99.

Rehman, J.U., Ali, A., Khan, I.A., 2014. Plant based products: use and development as repellents against mosquitoes: a review. Fitoterapia 95, 65-74.

Ritchie, S.A., Devine, G.J., 2013. Confusion, knock-down and kill of Aedes aegypti using metofluthrin in domestic settings: a powerful tool to prevent dengue transmission? Parasit. Vectors 6, 262.

Rozendaal, J.A., World Health Organization, 1997. Vector Control: Methods for Use by Individuals and Communities. World Health Organization, Geneva.

Tak, J.-H., Isman, M.B., 2015. Enhanced cuticular penetration as the mechanism for synergy of insecticidal constituents of rosemary essential oil in Trichoplusia ni. Sci. Rep. U.K. 5, 12690.

Tak, J.-H., Jovel, E., Isman, M.B., 2015. Comparative and synergistic activity of Rosmarinus officinalis $L$. essential oil constituents against the larvae and an ovarian cell line of the cabbage looper, Trichoplusia ni (Lepidoptera: Noctuidae). Pest Manag. Sci. 72, 474-480.

Tong, F., Bloomquist, J.R., 2013. Plant essential oils affect the toxicities of carbaryl and permethrin against Aedes aegypti (Diptera: Culicidae). J. Med. Entomol. 50, 826-832.

Tozzi, A., 1999. A brief history of the development of piperonyl butoxide as an insecticide synergist. In: Jones, D.G. (Ed.), Piperonyl Butoxide. Academic Press, London, pp. 1-5. 
Xue, R.-D., Qualls, W.A., Phillips, J.D., Zhao, T.-Y., 2012. Insecticidal activity of five commercial mosquito coils against Anopheles albimanus, Aedes albopictus, and Culex quinquefasciatus. J. Am. Mosq. Control Assoc. 28, 131-133.

Zar, J.H., 2007. Biostatistical Analysis, 5th edition. Pearson, Upper Saddle River, NJ.

Zhu, K.Y., Gao, J.-R., 1998. Kinetic properties and variability of esterases in organophosphate-susceptible and -resistant greenbugs, Schizaphis graminum (Homoptera: Aphididae). Pestic. Biochem. Physiol. 62, 135-145.

Zhu, K.Y., Gao, J.-R., Starkey, S.R., 2000. Organophosphate resistance mediated by alterations of acetylcholinesterase in a resistant clone of the greenbug, Schizaphis graminum (Homoptera: Aphididae). Pestic. Biochem. Physiol. 68, 138-147. 